\title{
Study of gala apples (Malus pumila) thin-layer microwave drying: drying kinetics, diffusivity, structure and color
}

\author{
Karim KRIAA ${ }^{1,2}$, Ahmed Fayez NASSAR ${ }^{1,3 *}$ (iD
}

\begin{abstract}
The effect of microwave power, sample thickness, and diameter on drying kinetics, effective moisture diffusivity, and activation energy of apple cylinders for microwave drying were investigated. Also, the effect of the microwave power on the quality of the dried apples was studied by measuring the surface color change and scanning the surface structure. The same mass of fresh apples was dried at different power levels. Two diameters and three thicknesses were studied. Aghbashlo model showed the best fitting for the drying kinetics of apple. The drying time was reduced by increasing the power and the diameter, but the thickness had no clear effect. The effective diffusivity values ranged between $1.47 \times 10^{-7}$ and $24.4 \times 10^{-7} \mathrm{~m}^{2} / \mathrm{s}$. The effective diffusivity increased by increasing the three studied parameters. The parameters' effects on the drying time and the diffusivity were studied using a full factorial experimental design. The power and the diameter had the highest effect on the drying time. However, the thickness had the highest effect on the effective diffusivity.
\end{abstract}

Keywords: microwave drying; kinetics; color change; SEM; design of experience.

Practical Application: The microwave drying parameters of apple slices, were tested in order to study their effect on the color and structure of the dried product. The best quality obtained with the most adequate drying kinetics (lower energy cost) corresponds to a microwave power of $500 \mathrm{~W}$.

\section{Introduction}

Drying is one of the oldest techniques to extend the shelf life of foods. It involves a simultaneous transfer of mass and heat; to reduce the moisture of products. Consequently, a decrease in free water available for weathering reactions; to keep a water activity $\left(a_{\mathrm{w}}\right)$ below the minimum activity of microorganism development (i.e. $a_{\mathrm{w}}<0.7$ ). Often it is necessary to go to lower values of $a_{\mathrm{w}}$ in order to inhibit chemical and enzymatic reactions of alteration (lipid oxidation, Maillard reactions, etc.) (Labuza et al., 1972). Optimization of the drying operation must meet two essential criteria, which are the energy cost and the preservation of the biological quality of the final product (color, taste, aroma, smell, texture, nutritional quality, techno-functional properties, etc.). Convective drying generally affects the quality of the product by thermal degradation of specific compounds due to high temperatures and prolonged drying times (Balti et al., 2018). To overcome these problems, the food industry has been interested in microwave drying. One of the most important characteristics of the use of microwaves is the volume heating effect; the energy is more absorbed in the wet region than in the dry region of the product (Khraisheh et al., 1997).

Microwave drying reduces drying time and energy cost with an improvement in the final quality of the dried product (color, aroma, and texture). In addition, the final product is more homogeneous and evenly dried (Polat et al., 2019). On the other hand, the microwave drying has some disadvantages; mainly due to the overheating of the product at a high power. Overheating can alter the texture associated with physical damage such as carbonizing and blackening of the product by Maillard reaction or the appearance of an unpleasant odor in the dried product (Beaudry et al., 2003).

Experimental studies on the drying of the food products were extensively studied in literature in order to understand the different phenomena affecting the kinetics to optimize the operation for the best product quality with the least energy consumption (Sanga et al., 2000) and (Orsat et al., 2006). Several mathematical models have been proposed to describe the drying kinetics (Ertekin \& Firat, 2017).

Many experimental works have been published to study the drying kinetics of apples using different drying methods and their effect on the quality of the dried apples. Ben Mabrouk et al. (2012) tested the effect of air temperature and velocity during convective drying on the characteristics of apple slices. Cuccurullo et al. (2018) studied the effect of controlling the temperature during microwave drying on the quality of sliced apples. Djekic et al. (2018) compared the effects of drying apples using three technologies (supercritical $\mathrm{CO}_{2}$ drying, air drying and freeze drying) on the quality of dried apples. Ando et al. (2019) evaluated the effects 
of prefreezing on the drying rate and the properties of apple dried by vacuum microwave. Polat et al. (2019) investigated the effect of microwave-vacuum drying on drying characteristics, protein, mineral content, and color of dried apples. However, it is seen that there is scarcity in studying the effect of variation of volume per unit mass of the apple samples on the microwave drying parameters. Also, few researchers investigated the effect of the microwave power on the surface color and structure of the dried apple samples.

The purpose of this research is to investigate the effect of thickness and diameter of apple cylinders of the same mass on the drying kinetics of Gala apple at three microwave power levels. Kinetic data were fitted to eight drying models reported in the literature. The effective moisture diffusivity and the activation energy were evaluated as well. An experimental design was applied to test the effect of the three studied parameters (the microwave power, the diameter and the thickness of the samples) on the drying time and diffusivity. Finally, the effect of the microwave power on the surface quality of the dried apples was studied by measuring the color change and investigating the structure of the dried apples using a scanning electron microscope (SEM).

\section{Materials and methods}

\subsection{Sample preparation}

Cylindrical samples of fresh Gala apple from the species (Malus pumila) were prepared. In order to study the effect of the size on the microwave drying kinetics, two diameters: $10.5 \pm 0.2$ and $17.5 \pm 0.3$, and three thicknesses: $3.3 \pm 0.2,4.5 \pm 0.2$ and $6.0 \pm 0.2 \mathrm{~mm}$ were prepared.

\subsection{Experimental setup and methods of drying}

Samples of about $23 \mathrm{~g}$ of apple were dried in a microwave oven (Microwave Research \& Applications BP-090/50), operating at a constant frequency of $2.45 \mathrm{GHz}$ and variable power (360, 500 , and 775 Watt). The adjustment of microwave power was made by a digital control unit built in the microwave oven.

The initial moisture content of apples $(88.43 \pm 0.89 \%)$ was determined by oven drying method (Association of Official Agricultural Chemists, 2010) using ELE international oven

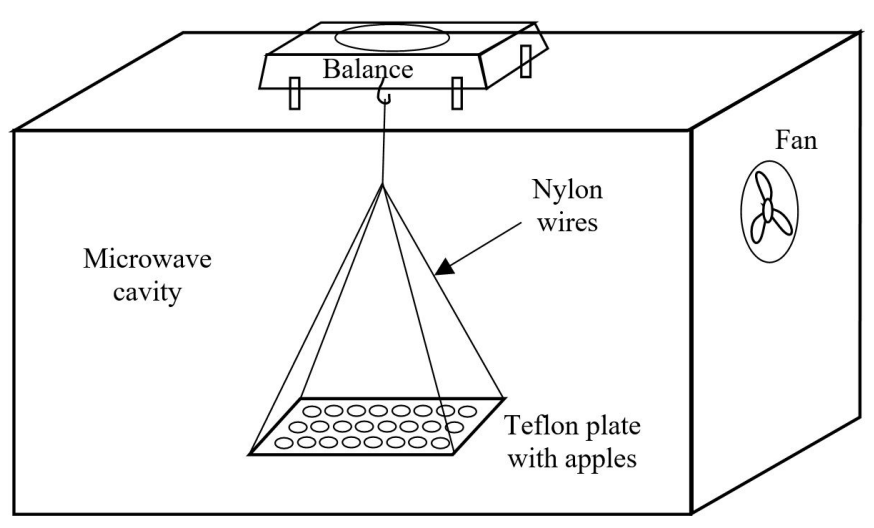

Figure 1. Schematic diagram of the microwave drying setup.
(SDO/225/DIG) at $105^{\circ} \mathrm{C}$ for 24 hours until the mass did not change significantly between two weighing successions. The drying kinetics were determined by continuous measurement of mass using a $10^{-2} \mathrm{~g}$ electronic precision balance (OHAUS AT400) versus time.

The apple cylinders were arranged over a rectangular polytetrafluoroethylene (PTFE) plate, which was suspended inside the microwave via nylon wires connected to the balance. The mass of the sample was recorded manually every one minute. Figure 1 shows a schematic presentation of the drying experiment.

All drying curves are presented as Moisture Ratio $(M R)$ as a function of drying time. The $M R$ is calculated from Equation 1:

$M R=\frac{M-M_{e}}{M_{0}-M_{e}}$

where $M$ : the moisture content at any time, $M_{0}$ : the initial moisture content, and $M_{e}$ : moisture content at the equilibrium.

However, according to Dissa et al. (2011), Sallam et al. (2015), and others, $M_{\mathrm{e}}$ is relatively small compared to $M_{0}$ and $M$; thus, it could be neglected. Therefore, Equation 2 was used to calculate the $M R$ :

$M R=\frac{M}{M_{0}}$

The drying rate is presented as a function of reduced moisture content using Equation 3:

$\left(\frac{d M}{d t}\right)_{r}=\frac{M_{t+\Delta t}-M_{t}}{d t}$

where $M_{\mathrm{t}+\Delta \mathrm{t}}$ is the moisture content at time $t+\Delta t$, and $M_{\mathrm{t}}$ is the moisture content at time $t$.

\subsection{Determination of drying time using an experimental design}

An experimental design was used to test the effect of the three factors studied and their interactions on microwave drying. Table 1 shows the different levels for each factor used in this work.

The drying time of samples until $M R=0.07$ on a wet basis and the effective diffusivity were chosen as experimental responses for this study. They were modeled using Equation 4:

Response $=\beta_{0}+\sum_{i=1}^{n} \beta_{i} \cdot X_{i}+\sum_{i=1}^{n} \sum_{j=1}^{n} \beta_{i j} \cdot X_{i} \cdot X_{j}+\varepsilon$

where $b_{0}$ is the constant term, $b_{\mathrm{i}}$ and $b_{\mathrm{ij}}$ are the regression coefficients, $\varepsilon$ is the error between calculated and experimental data, $X_{\mathrm{i}}$ and $X_{\mathrm{j}}$ are the factors, and $n$ is factors number.

A reduced regression model, showing only the significant variables, was determined after testing coefficients by the analysis of variance test (ANOVA) at 95\% significance level $(p<0.05)$. 
The design and all analysis of the full factorial design were performed with Statistica12.

\subsection{Mathematical models}

As stated by Fortes \& Okos (1981), thin-layer drying modeling of agricultural products assumes that (1) the resistance to the transfer of matter is uniformly distributed in the homogeneous isotropic material, (2) the effective diffusivity coefficient, $D_{\text {eff }}$ is independent of the local moisture content, and (3) the variation of the volume is negligible. Then, the second law of Fick can be written as in Equation 5:

$$
\frac{\partial M}{\partial t}=D_{e f f} \nabla^{2} M
$$

Eight semi-theoretical and numerical models mostly deduced from the second law of Fick's law were evaluated to fit the experimental work. These models - listed in Table 2 - were used in studies of drying kinetics using microwave by several researchers (Özbek \& Dadali, 2007; Darvishi et al., 2014; Zarein et al., 2015; Ashtiani et al., 2018; Sin Ying et al., 2018), and (Polat et al., 2019).

\subsection{Statistical tests of fitting quality}

Experimental kinetics data were used to fit the studied models using nonlinear least-squares regression method. Regression was carried out using Matlab, R2018a (The MathWorks, Inc.). The coefficient of determination $\left(R^{2}\right)$, the adjusted $R^{2}\left(R^{2}(\operatorname{adj})\right)$ and the root mean square error (RMSE) show the fitting quality of models as described by Equations 6-8:

$$
\begin{aligned}
& R^{2}=1-\frac{\sum_{i=1}^{n}\left(Y_{i}-\hat{Y}_{i}\right)^{2}}{\sum_{i=1}^{n}\left(Y_{i}-\overline{Y_{i}}\right)^{2}} \\
& R^{2}(a d j)=1-\left(R^{2} \cdot \frac{d f_{I}}{d f_{2}}\right)
\end{aligned}
$$

$$
R M S E=\sqrt{\frac{\sum_{i=I}^{n}\left(Y_{i}-\hat{Y}_{i}\right)^{2}}{n}}
$$

where $Y_{i}$ is experimental value, $\hat{Y}_{i}$ is calculated value by using regression model, $\bar{Y}_{i}$ is arithmetic average of experimental value, $\mathrm{n}$ is the number of experimental points, and $d f_{1}$ and $d f_{2}$ are respective degrees of freedom of the error sum of the squares and the total sums of the squares of the regression model.

All models coefficients were calculated with $95 \%$ confidence limits (i.e. $\mathrm{p}<0.05$ ).

\subsection{Calculation of effective diffusivity}

The solution of Fick's second law (Equation 4) for an infinite slab has been reported by several researchers with the following

Table 1. Coded values for factor's levels.

\begin{tabular}{lcccc}
\hline \multirow{2}{*}{ Factor } & Coded Factor & \multicolumn{3}{c}{ Level } \\
\cline { 3 - 5 } & & -1 & 0 & 1 \\
\hline Power P (Watt) & $\mathrm{X}_{1}$ & 360 & 500 & 775 \\
Diameter D (mm) & $\mathrm{X}_{2}$ & 10.5 & - & 17.5 \\
Thickness t (mm) & $\mathrm{X}_{3}$ & 3.3 & 4.5 & 6 \\
\hline
\end{tabular}

Table 2. Models used to describe the drying kinetics.

\begin{tabular}{cccc}
\hline No. & Name & Reference & Model \\
\hline 1 & Lewis (Newton, exponential) & (Lewis, 1921) & MR=exp $(-k t)$ \\
2 & Page & (Page, 1949) & $M R=\exp \left(-k t^{n}\right)$ \\
3 & Henderson and Pabis & (Henderson \& Pabis, 1961) & $M R=a \cdot \exp (-k t)$ \\
4 & Logarithmic & (Hukill, 1954) & $M R=a \cdot \exp (-k t)+c$ \\
5 & Modified Two-Term exponential & $($ Sharaf-Eldeen et al., 1980) & $M R=a \cdot \exp (-k t)+(1-a) \cdot \exp (-k a t)$ \\
6 & Parabolic (Wang \& Singh) & (Wang \& Singh, 1978) & $M R=1+a t+b t^{2}$ \\
7 & Verma & (Verma et al., 1985) & $M R=a \cdot \exp (-k t)+(1-a) \cdot \exp (-g t)$ \\
\end{tabular}


assumptions: (1) internal moisture migrates by diffusion; (2) negligible shrinkage; and (3) negligible external and internal heat transfer effects (Crank, 1975). The solution is presented in Equation 9:

$M R=\frac{8}{\pi^{2}} \sum_{n=1}^{\infty} \frac{1}{(2 n-1)^{2}} \exp \left(\frac{-(2 n-1)^{2} \pi^{2} D_{e f f} t}{4 L^{2}}\right)$

where $D_{\text {eff }}$ is the effective moisture diffusivity, $t$ is time, $L$ is the thickness of the slab, and $n$ is the positive integer.

For long drying times, Equation 9 can be simplified by taking the first term of the series to obtain Equation 10, which was used to evaluate the effective diffusivity for each experiment.

$$
M R=\frac{8}{\pi^{2}} \exp \left(-\frac{\pi^{2} D_{e f f} t}{4 L^{2}}\right)
$$

\subsection{Calculation of activation energy}

Since the drying temperature was not measured in this study, the modified Arrhenius equation (Equation 11) derived by Özbek \& Dadali (2007) was used to demonstrate the relationship between the effective diffusivity and the ratio of the microwave power to sample mass. This equation was used to calculate the activation energy and the pre-exponential factor.

$$
D_{\text {eff }}=D_{0} \exp \left(\frac{-E_{a} \cdot m}{P}\right)
$$

where $D_{0}\left(\mathrm{~m}^{2} / \mathrm{s}\right)$ is pre-exponential factor, $P$ is the microwave power (W), $m$ is the mass of the initial sample (g), and $E_{\mathrm{a}}$ is the activation energy $(\mathrm{W} / \mathrm{g})$.

\subsection{Color measurement}

The surface color of both fresh and dried apple cylinders was determined by a Minolta CR-400 Chroma Meter (Japan). Three color measurements were taken for each sample, resulting in values for three chromatic scales $\left(\mathrm{L}^{*}, \mathrm{a}^{*}, \mathrm{~b}^{*}\right)$. Where $\mathrm{L}^{\star}$ indicates lightness ranging from no reflection for black $\left(\mathrm{L}^{*}=0\right)$ to perfect reflection for white $\left(\mathrm{L}^{*}=100\right), \mathrm{a}^{*}$ is the red/green coordinate with negative values for green to positive values for red, and $\mathrm{b}^{\star}$ is the yellow/blue coordinate with negative values for blue and positive values for yellow. The color difference between the dried and fresh samples, $\Delta E$, was calculated according to Equation 12.

$$
\Delta E=\sqrt{\Delta L^{2}+\Delta a^{2}+\Delta b^{2}}
$$

\subsection{Visualization of the structure of the samples}

Structure Characterization was performed with a Variable Pressure Scanning Electron Microscope (SEM) Hitachi S-3400N model (Hitachi High-Technologies, Japan). Analysis was performed at vacuum with a primary beam power of $20 \mathrm{kV}$ and $30 \mathrm{~mA}$.

\section{Results and discussion}

A total of eighteen drying experiments were conducted covering all the possible combinations of the studied variables. Some experiments were done in replicates to check their reproducibility. Three different power levels, 360, 500, and $775 \mathrm{~W}$, were used for drying about $23 \mathrm{~g}$ of apple cylinders having 10.5 and $17.5 \mathrm{~mm}$ diameters and $3.3,4.5$, and $6.0 \mathrm{~mm}$ thickness. The initial moisture content $\left(\mathrm{M}_{0}\right)$ was measured four times, with an average value, $88.4 \%( \pm 0.8 \%)$. The apple samples were dried until the moisture content was below $7 \%$. The time to reach $7 \%$ moisture content varied between 12 and 59 minutes, depending on the studied variables.

\subsection{Effect of microwave power on the drying kinetics}

Figure 2 shows the moisture ratio on a wet basis as a function of the drying time in minutes for all runs. The drying time for the same sample size was clearly reduced by increasing the microwave power. Polat et al. (2019) and Sin Ying et al. (2018) reported similar results for microwave drying of apples and bananas, respectively. For the same thickness and diameter, the drying time to reach a moisture content of $7 \%$ was shortened in average by $54.7 \pm 2.5 \%$ upon increasing the power from 360 $\mathrm{W}$ to $775 \mathrm{~W}$. This result was expected because of the higher amount of heat generated within the sample at the higher microwave power.

\subsection{Effect of sample size on the drying kinetics}

As shown in Figure 3, for the same microwave power, the drying time is reduced by increasing the diameter from 10.5 to $17.5 \mathrm{~mm}$ for all runs. The reduction percentages in the drying time varied between $28 \%$ and $49 \%$. However, there was no apparent effect of changing the thickness on the drying curves.

\subsection{Modelling results for the drying kinetics}

The eight models listed in Table 2 were tested for all the drying experiments. All tested models showed good fitting $\left(R^{2}\right.$ (adj) $>0.9391)$. However, three models clearly exhibited better fitting than the others with $R^{2}($ adj $)>0.99$ and $R M S E<0.0342$ for all runs. These models are Aghbashlo, Page, and Logarithmic models (respectively with an average of $R^{2}$ (adj) value of 0.9987 , 0.9982 and 0.9977 , and average RMSE value of $0.01034,0.012219$ and 0.0135 ). Table 3 shows the corresponding results of nonlinear regression and statistical parameters for all experiments for the best three models.

All obtained results from the Aghbashlo model were compared with the experimental data and presented in Figure 4. The scatter plot is very close to the first bisector $(x=y)$ with a variance not exceeding the half-band of $5 \%$ $(p<0.05)$. Despite the measurement errors that may occur due to the heterogeneity of the raw material itself, a high correlation coefficient between the proposed model and the experimental data has been observed in all the cases with an average of $R^{2}$ (adj) $=0.9987$. 

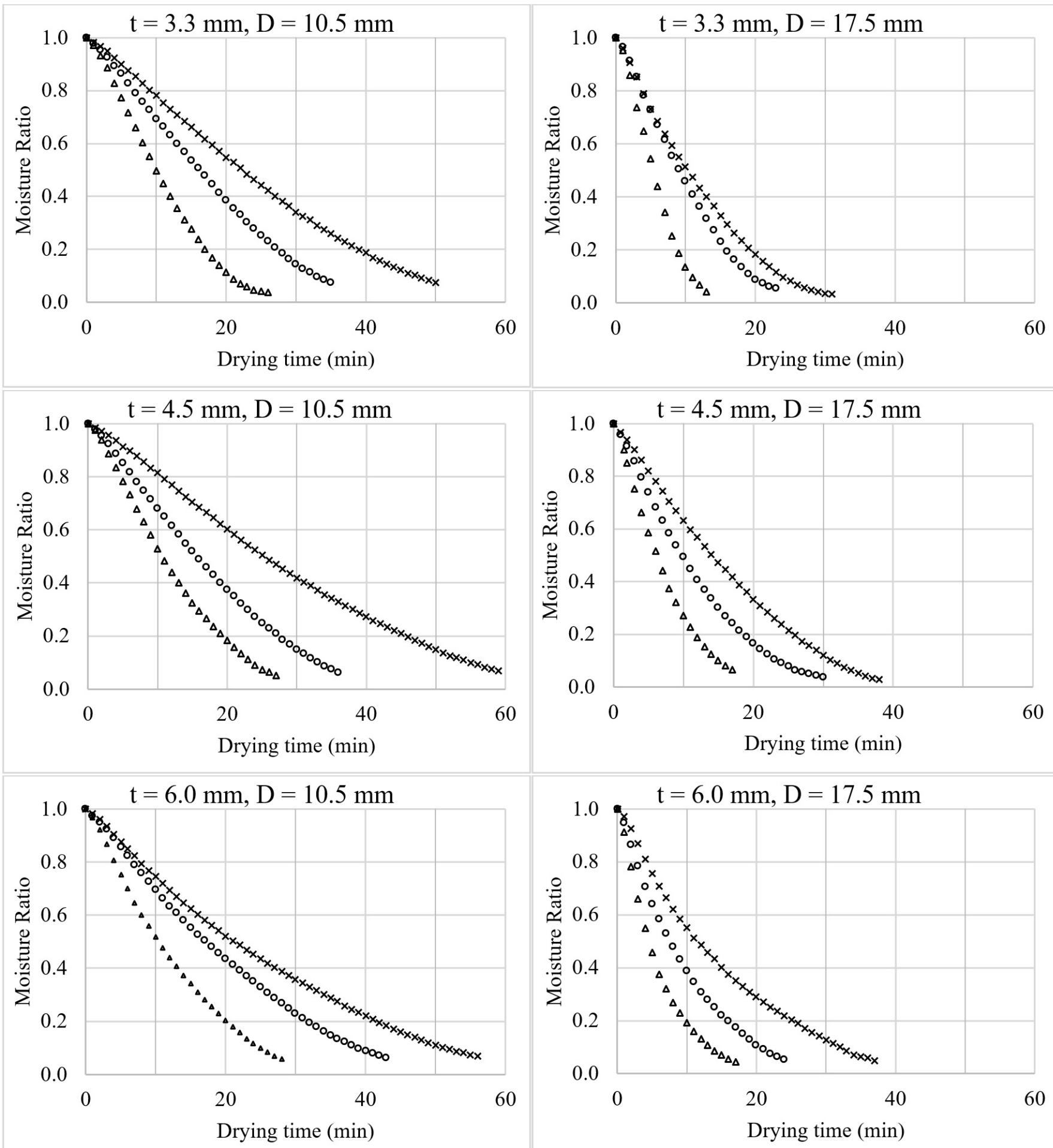

\section{$\times 360 \mathrm{~W} \circ 500 \mathrm{~W} \triangle 775 \mathrm{~W}$}

Figure 2. Drying kinetics of apple cylinders at different microwave powers, samples thickness, and diameter.

\subsection{Determination of the effective diffusivity and activation energy}

The effective diffusivity $D_{\text {eff }}$ for apple samples was calculated for all runs. $D_{\text {eff }}$ values were proportional to microwave power, thickness of the samples, and diameter of the samples for all runs.
$D_{\text {eff }}$ values are presented in Table 4 , where they ranged between $1.47 \times 10^{-7}$ and $24.4 \times 10^{-7} \mathrm{~m}^{2} / \mathrm{s}$. These values are in perfect agreement with Zarein et al. (2015), who studied microwave drying of apples. These values are also in good agreement with Ashtiani et al. (2018) and Darvishi et al. (2014), who dried other fruits with the microwave. 


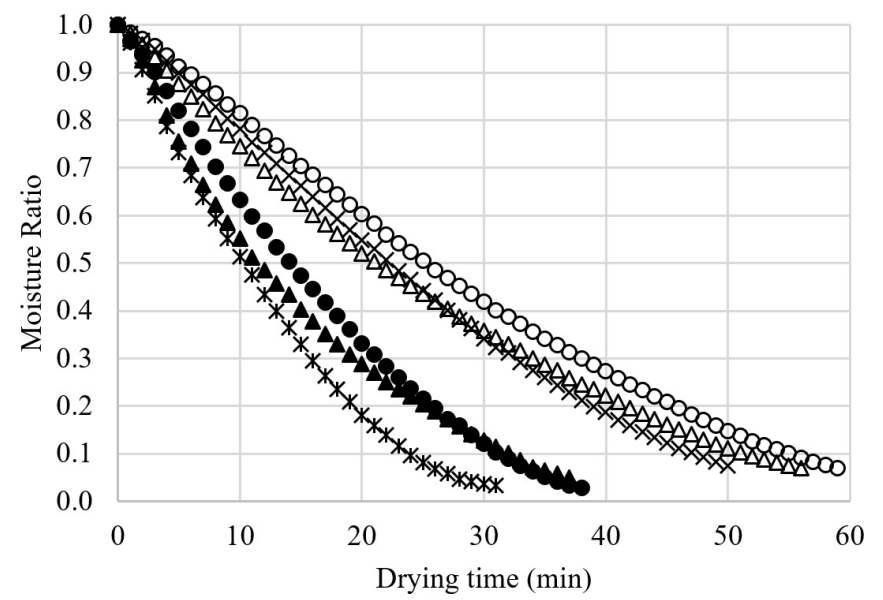

(a)

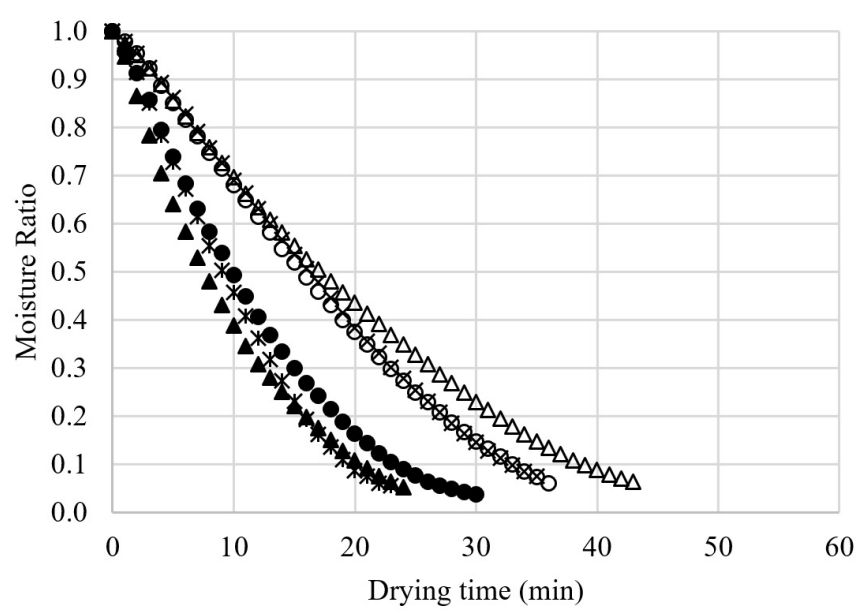

(b)

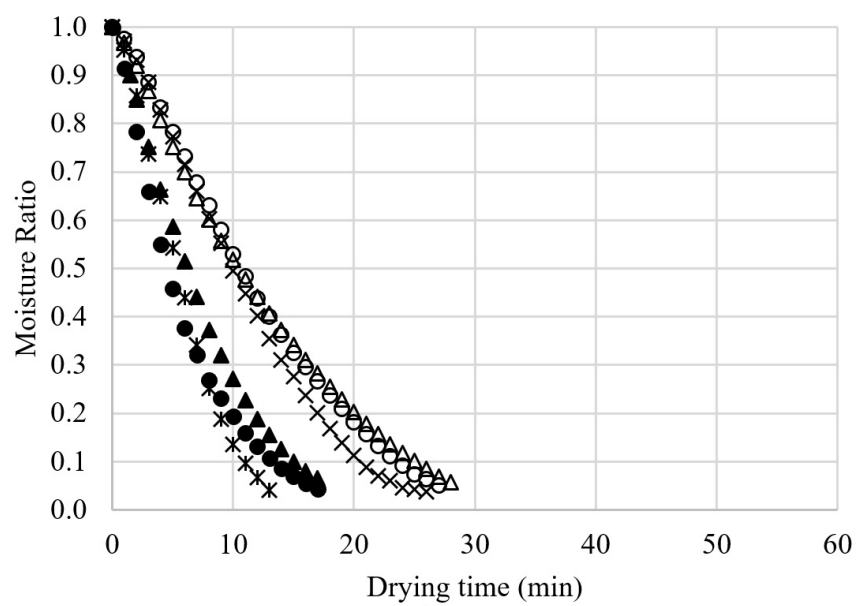

(c)

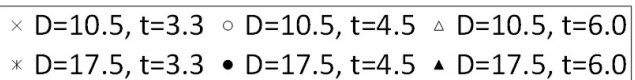

Figure 3. Effect of sample size on drying kinetics of apple cylinders for (a) $360 \mathrm{~W}$, (b) $500 \mathrm{~W}$, and (c) $775 \mathrm{~W}$.

The activation energy was calculated by plotting the natural logarithm of the effective diffusivity, $\ln \left(D_{\text {eff }}\right)$, versus mass per power, $m / P$, at the same diameter and thickness. All the plots produced straight lines with $0.948<R^{2}<0.999$, indicating that activation energy profiles follow the modified Arrhenius equation (Equation 11). The calculated activation energy was between 19.2 and $27.1 \mathrm{~g} / \mathrm{W}$ for the studied conditions, which is in good agreement with Zarein et al. (2015) and Darvishi et al. (2014).

\subsection{Full factorial experimental design for the drying experiments}

The studied responses vary with the experimental conditions, so ANOVA test is applicable in our case. The application of this statistical test allows the determination of a multi-linear dependence on the response of the tested factors (significations and interactions). Table 5 presents the result of ANOVA test. For the drying time, the power $(\mathrm{P})$, the diameter $(D)$, the thickness $(t)$, the quadratic power $\left(P^{2}\right)$, and the interaction power diameter $(P \times D)$ are significant, with a $p$-value $<0.05$. However, for the effective diffusivity, all effects are significant with a $p$-value $<0.05$ except the quadratic power $\left(P^{2}\right)$ and the quadratic diameter $\left(D^{2}\right)$.

The results show that the main factors for drying time are the power and the diameter, and they appear in negative signs, which means that increasing their values reduces the drying time. Afterward, and with less effect, we find the quadratic power, the interaction power diameter, and then the thickness. These results are in agreement with the observation made from the drying kinetics curves shown in Figures 2 and 3. For the effective diffusivity, all parameters have positive signs, which means proportional correlation between effective diffusivity and all parameters. Results show also that thickness is the most effective factor, which is in good agreement with the observations made above in Section 3.4.

The validity of the two models is confirmed by the coefficient of determination, $R^{2}$, of $98.43 \%$ and $96 \%$ for the drying time and diffusivity, respectively, and the adjusted coefficient of determination, $R^{2}$ (adj), of $97.03 \%$ and $93.09 \%$ for the drying time and diffusivity, respectively. Therefore, maintained models are expressed by Equations 13 and 14:

Time $=26.57-23.64 \cdot P-16.12 \cdot D+13.21 \cdot P^{2}+6.40 \cdot P \cdot D+5.53 \cdot t$

Diffusivity $=4.65+4.37 \cdot t+2.76 \cdot P+2.26 \cdot D+1.98 \cdot t \cdot P+1.89 \cdot t^{2}+1.63 \cdot D \cdot t+0.99 \cdot D \cdot P$

\subsection{Effect of the microwave power on the surface color change}

The surface color of the dried samples is a significant factor for its quality. This is the first parameter for the evaluation of the product, even before the taste. After microwave drying, samples were photographed (Figure 5). It is noted that the color of the samples is not uniform; this is due to the non-uniformity of the microwave emission beam distribution. It can be seen from Figure $5 c$, $d$ that at high powers, the samples placed in the center of the plate were burned. So during our analysis of the color, the central samples are avoided.

The CIE L*, $\mathrm{a}^{*}$, and $\mathrm{b}^{*}$ average values for the fresh apple samples were $71.2,-2.5$, and 15.1, respectively. The changes of the three values were toward darker $(\Delta L=$ negative $)$, more red $(\Delta a=$ positive $)$, and more yellow $(\Delta b=$ positive $)$ dried product. The average changes in lightness $(\Delta L)$ and total color $(\Delta E)$ for the dried samples were -6.33 and 11.23 at $360 \mathrm{~W},-7.95$ and 13.31 at $500 \mathrm{~W}$ and -8.94 and 15.52 at $775 \mathrm{~W}$, respectively. These results are in accordance 
Table 3. Coefficients and statistical parameters of drying modeling for Aghbashlo, Page and Logarithmic models.

\begin{tabular}{|c|c|c|c|c|c|c|c|c|}
\hline \multirow{2}{*}{ Exp. } & \multirow{2}{*}{ Model } & \multicolumn{5}{|c|}{ Coefficient } & \multirow{2}{*}{ Adj. $R^{2}$} & \multirow{2}{*}{ RMSE } \\
\hline & & $\mathrm{k}_{1}$ & $\mathrm{k}_{2}$ & $\mathrm{a}$ & $\mathrm{c}$ & $\mathrm{n}$ & & \\
\hline 1 & \multirow{20}{*}{$M R=\exp \left[-\frac{k_{1} t}{\left(1+k_{2} t\right)}\right]$} & 0.058 & -0.014 & - & - & - & 0.9993 & 0.00765 \\
\hline $1^{\prime}$ & & 0.055 & -0.018 & - & - & - & 0.9996 & 0.00612 \\
\hline 2 & & 0.057 & -0.027 & - & - & - & 0.9986 & 0.01162 \\
\hline 3 & & 0.089 & -0.056 & - & - & - & 0.9952 & 0.02355 \\
\hline 4 & & 0.038 & -0.015 & - & - & - & 0.9997 & 0.00489 \\
\hline 5 & & 0.058 & -0.018 & - & - & - & 0.9991 & 0.00937 \\
\hline $5^{\prime}$ & & 0.058 & -0.019 & - & - & - & 0.9985 & 0.01195 \\
\hline 6 & & 0.092 & -0.028 & - & - & - & 0.9981 & 0.01341 \\
\hline 7 & & 0.054 & -0.008 & - & - & - & 0.9985 & 0.01102 \\
\hline 8 & & 0.081 & -0.013 & - & - & - & 0.9992 & 0.00812 \\
\hline 9 & & 0.138 & -0.017 & - & - & - & 0.9971 & 0.01656 \\
\hline 10 & & 0.027 & -0.007 & - & - & - & 0.9994 & 0.00676 \\
\hline 11 & & 0.032 & -0.012 & - & - & - & 0.9996 & 0.00581 \\
\hline 12 & & 0.054 & -0.017 & - & - & - & 0.9991 & 0.00903 \\
\hline 13 & & 0.048 & -0.022 & - & - & - & 0.9978 & 0.01460 \\
\hline 14 & & 0.032 & -0.016 & - & - & - & 0.9993 & 0.00766 \\
\hline 15 & & 0.020 & -0.009 & - & - & - & 0.9992 & 0.00792 \\
\hline 16 & & 0.023 & -0.011 & - & - & - & 0.9994 & 0.00683 \\
\hline 17 & & 0.030 & -0.018 & - & - & - & 0.9994 & 0.00755 \\
\hline 18 & & 0.049 & -0.027 & - & - & - & 0.9975 & 0.01639 \\
\hline 1 & \multirow[t]{2}{*}{ Page } & 0.041 & - & - & - & 1.230 & 0.9974 & 0.01498 \\
\hline $1^{\prime}$ & & 0.034 & - & - & - & 1.311 & 0.9971 & 0.01653 \\
\hline 2 & \multirow[t]{18}{*}{$M R=\exp \left(-k t^{n}\right)$} & 0.029 & - & - & - & 1.453 & 0.9983 & 0.01309 \\
\hline 3 & & 0.046 & - & - & - & 1.630 & 0.9992 & 0.00991 \\
\hline 4 & & 0.019 & - & - & - & 1.380 & 0.9963 & 0.01855 \\
\hline 5 & & 0.034 & - & - & - & 1.324 & 0.9992 & 0.00863 \\
\hline $5^{\prime}$ & & 0.034 & - & - & - & 1.340 & 0.9993 & 0.00840 \\
\hline 6 & & 0.065 & - & - & - & 1.311 & 0.9997 & 0.00517 \\
\hline 7 & & 0.043 & - & - & - & 1.135 & 0.9980 & 0.01276 \\
\hline 8 & & 0.066 & - & - & - & 1.165 & 0.9991 & 0.00890 \\
\hline 9 & & 0.117 & - & - & - & 1.159 & 0.9990 & 0.00991 \\
\hline 10 & & 0.016 & - & - & - & 1.233 & 0.9974 & 0.01436 \\
\hline 11 & & 0.016 & - & - & - & 1.330 & 0.9973 & 0.01503 \\
\hline 12 & & 0.034 & - & - & - & 1.292 & 0.9984 & 0.01169 \\
\hline 13 & & 0.023 & - & - & - & 1.443 & 0.9991 & 0.00905 \\
\hline 14 & & 0.013 & - & - & - & 1.445 & 0.9977 & 0.01431 \\
\hline 15 & & 0.008 & - & - & - & 1.402 & 0.9980 & 0.01284 \\
\hline 16 & & 0.009 & - & - & - & 1.430 & 0.9978 & 0.01361 \\
\hline 17 & & 0.011 & - & - & - & 1.494 & 0.9971 & 0.01582 \\
\hline 18 & & 0.020 & - & - & - & 1.557 & 0.9989 & 0.01084 \\
\hline 1 & Logarithmic & 0.056 & - & 1.208 & -0.187 & - & 0.9991 & 0.00910 \\
\hline $1^{\prime}$ & \multirow{8}{*}{$M R=a \exp (-k t)+c$} & 0.054 & - & 1.266 & -0.237 & - & 0.9983 & 0.01250 \\
\hline 2 & & 0.050 & - & 1.510 & -0.467 & - & 0.9965 & 0.01867 \\
\hline 3 & & 0.075 & - & 1.701 & -0.644 & - & 0.9900 & 0.03416 \\
\hline 4 & & 0.033 & - & 1.442 & -0.414 & - & 0.9990 & 0.00969 \\
\hline 5 & & 0.059 & - & 1.242 & -0.201 & - & 0.9976 & 0.01507 \\
\hline $5^{\prime}$ & & 0.063 & - & 1.236 & -0.183 & - & 0.9968 & 0.01746 \\
\hline 6 & & 0.091 & - & 1.269 & -0.230 & - & 0.9969 & 0.01692 \\
\hline 7 & & 0.053 & - & 1.123 & -0.104 & - & 0.9992 & 0.00802 \\
\hline
\end{tabular}


Table 3. Continued...

\begin{tabular}{|c|c|c|c|c|c|c|c|c|}
\hline \multirow{2}{*}{ Exp. } & \multirow{2}{*}{ Model } & \multicolumn{5}{|c|}{ Coefficient } & \multirow{2}{*}{ Adj. $R^{2}$} & \multirow{2}{*}{ RMSE } \\
\hline & & $\mathrm{k}_{1}$ & $\mathrm{k}_{2}$ & $\mathrm{a}$ & $\mathrm{c}$ & $\mathrm{n}$ & & \\
\hline 8 & & 0.081 & - & 1.134 & -0.112 & - & 0.9994 & 0.00688 \\
\hline 9 & & 0.150 & - & 1.086 & -0.048 & - & 0.9973 & 0.01589 \\
\hline 10 & & 0.024 & - & 1.300 & -0.284 & - & 0.9998 & 0.00412 \\
\hline 11 & & 0.026 & - & 1.452 & -0.428 & - & 0.9993 & 0.00753 \\
\hline 12 & & 0.049 & - & 1.315 & -0.284 & - & 0.9992 & 0.00861 \\
\hline 15 & & 0.015 & - & 1.646 & -0.613 & - & 0.9989 & 0.00945 \\
\hline 16 & & 0.016 & - & 1.775 & -0.744 & - & 0.9987 & 0.01048 \\
\hline 17 & & 0.018 & - & 2.091 & -1.059 & - & 0.9982 & 0.01247 \\
\hline 18 & & 0.046 & - & 1.530 & -0.470 & - & 0.9937 & 0.02578 \\
\hline
\end{tabular}

Table 4. Design of Experience and results.

\begin{tabular}{|c|c|c|c|c|c|}
\hline Exp. & Power P (Watt) & Diameter D $(\mathrm{mm})$ & Thickness t (mm) & Time (min) & Diffusivity x $10^{7}\left(\mathrm{~m}^{2} / \mathrm{s}\right)$ \\
\hline 1 & $-1(360)$ & $1(17.5)$ & $-1(3.3)$ & 27.61 & 3.25 \\
\hline $1^{\prime}$ & $-1(360)$ & $1(17.5)$ & $-1(3.3)$ & 25.81 & 3.35 \\
\hline 2 & $0(500)$ & $1(17.5)$ & $-1(3.3)$ & 21.38 & 3.86 \\
\hline 3 & $1(775)$ & $1(17.5)$ & $-1(3.3)$ & 11.9 & 6.91 \\
\hline 4 & $-1(360)$ & $1(17.5)$ & $0(4.5)$ & 33.42 & 4.46 \\
\hline 5 & $0(500)$ & $1(17.5)$ & $0(4.5)$ & 25.56 & 6.51 \\
\hline 5 & $0(500)$ & $1(17.5)$ & $0(4.5)$ & 24.94 & 6.60 \\
\hline 6 & $1(775)$ & $1(17.5)$ & $0(4.5)$ & 16.63 & 9.89 \\
\hline 7 & $-1(360)$ & $1(17.5)$ & $1(6.0)$ & 34.26 & 9.88 \\
\hline 8 & $0(500)$ & $1(17.5)$ & $1(6.0)$ & 22.48 & 13.82 \\
\hline 9 & $1(775)$ & $1(17.5)$ & $1(6.0)$ & 14.99 & 24.44 \\
\hline 10 & $-1(360)$ & $-1(10.5)$ & $1(6.0)$ & 55.8 & 5.03 \\
\hline 11 & $0(500)$ & $-1(10.5)$ & $1(6.0)$ & 42.09 & 6.74 \\
\hline 12 & $1(775)$ & $-1(10.5)$ & $1(6.0)$ & 26.99 & 10.42 \\
\hline 13 & $1(775)$ & $-1(10.5)$ & $0(4.5)$ & 25.34 & 6.00 \\
\hline 14 & $0(500)$ & $-1(10.5)$ & $0(4.5)$ & 35.35 & 3.82 \\
\hline 15 & $-1(360)$ & $-1(10.5)$ & $0(4.5)$ & 58.92 & 2.36 \\
\hline 16 & $-1(360)$ & $-1(10.5)$ & $-1(3.3)$ & 50.64 & 1.47 \\
\hline 17 & $0(500)$ & $-1(10.5)$ & $-1(3.3)$ & 35.51 & 2.11 \\
\hline 18 & $1(775)$ & $-1(10.5)$ & $-1(3.3)$ & 22.06 & 3.42 \\
\hline
\end{tabular}

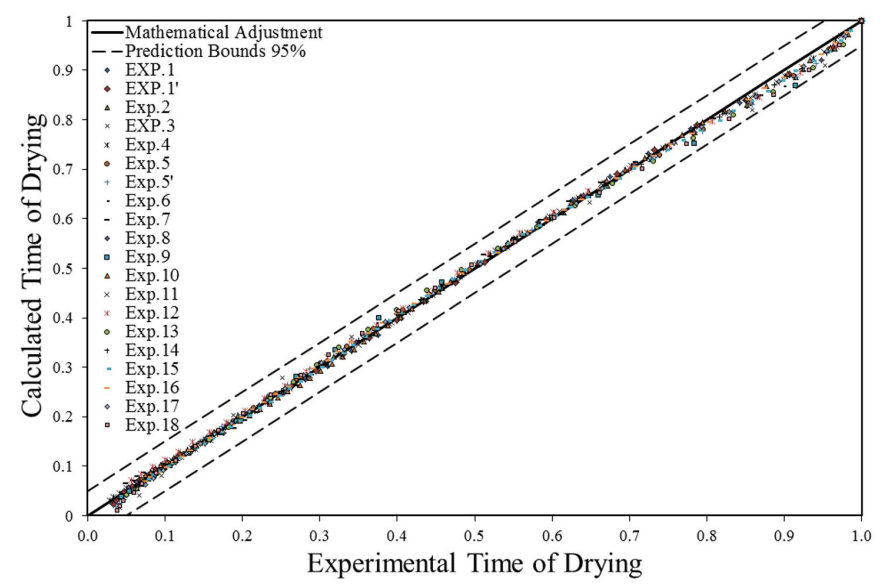

Figure 4. Calculated values by Aghbashlo model versus all experimental drying kinetics of apple samples. with the observations made during the experiments where it was noticed that browning occurred more at the higher microwave power levels (Figure 5). The same trend with similar values was observed for microwave drying of apple (Polat et al., 2019), mango (Izli et al., 2017) and ginger (Izli \& Polat, 2019).

\subsection{Effect of the microwave power on the structure of the samples}

SEM analysis can help understanding the effect of microwave drying on hardness, and therefore, product quality. Figures 6 and 7 show the microstructure of the dried apple samples at different microwave power levels.

The scanning electron micrographs of Figure 6 show a reduction in the size of the cells compared to the sample of the fresh apple (Figure 6a), which initially contains more water. We notice that as microwave power increases, cells exhibit 
Table 5. Analysis of variance for the factors and the interactions model of the responses.

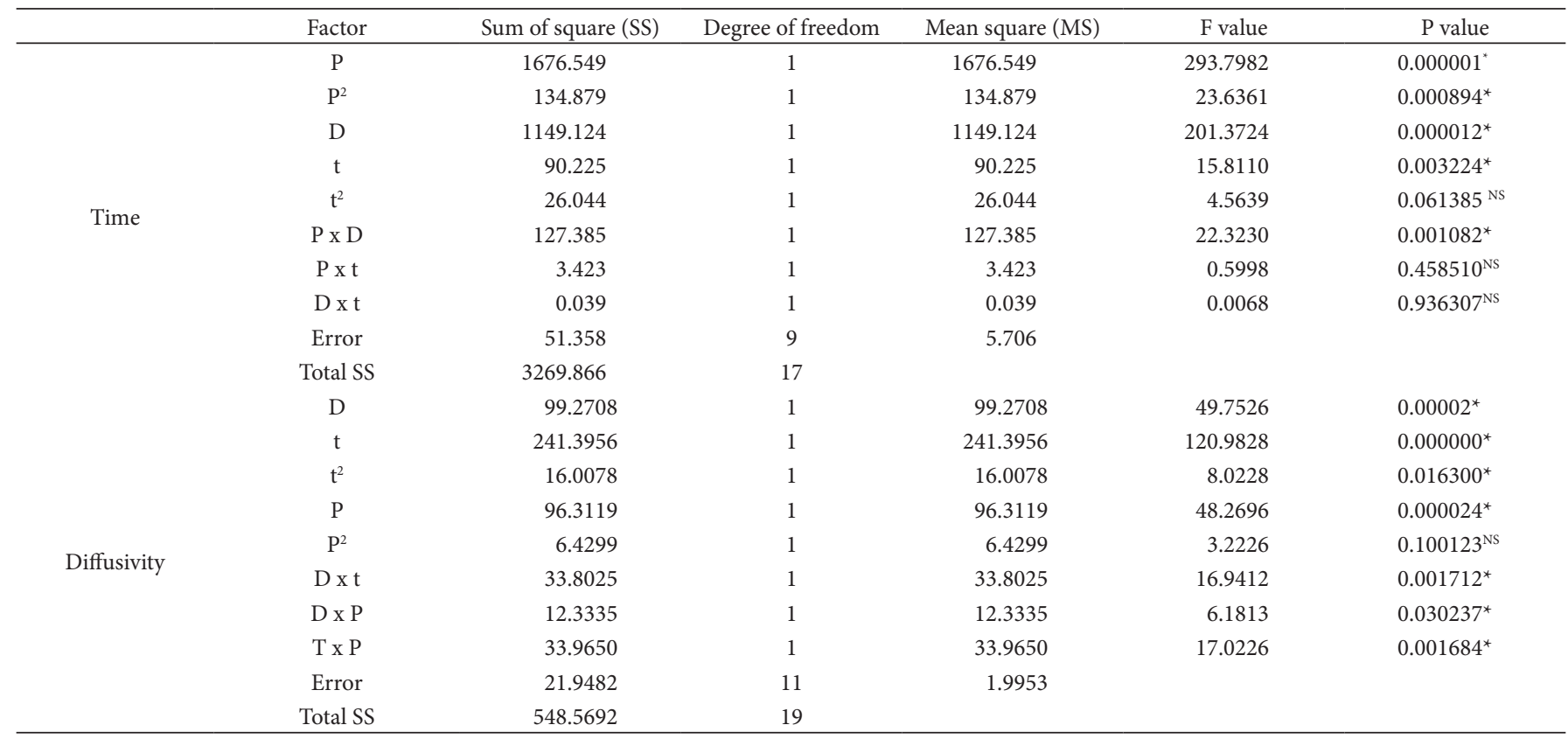

For Time $\mathrm{R}^{2}=98.43 \%, \mathrm{R}^{2}$ (adj) = 97.03\%; For Diffusivity $\mathrm{R}^{2}=96 \%, \mathrm{R}^{2}$ (adj) = 93.09\%; All variables are in coded units, $\mathrm{P}$ is the coded value of Power (Watt), D is the coded value of Diameter $(\mathrm{mm}), \mathrm{t}$ is the coded value of thickness ( $\mathrm{mm})$; NS not significant; ${ }^{\star}$ Significant at the level $5 \%$.

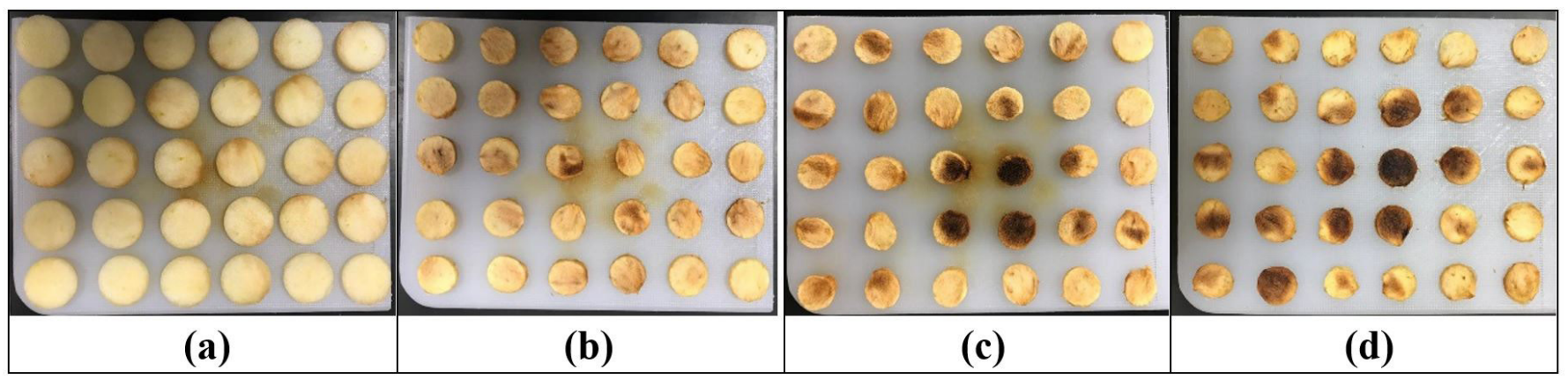

Figure 5. Photography of apple samples: Fresh (a) and after microwave drying at 360W (b), $500 \mathrm{~W}$ (c), and $775 \mathrm{~W}$ (d).

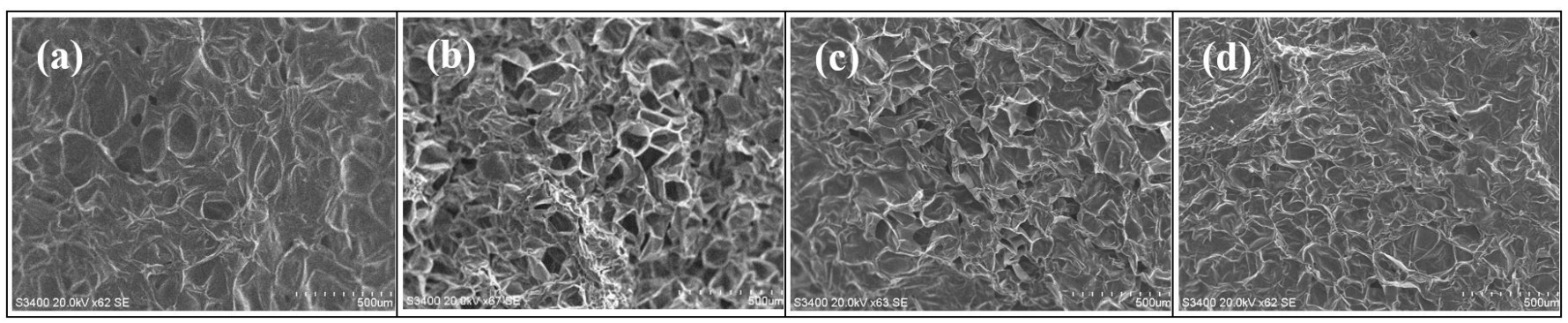

Figure 6. Scanning electron microscopy micrographs of apple samples at Magnification 62x: Fresh (a) and dried with microwave at 360W (b), $500 \mathrm{~W}(\mathrm{c})$, and $775 \mathrm{~W}(\mathrm{~d})$.

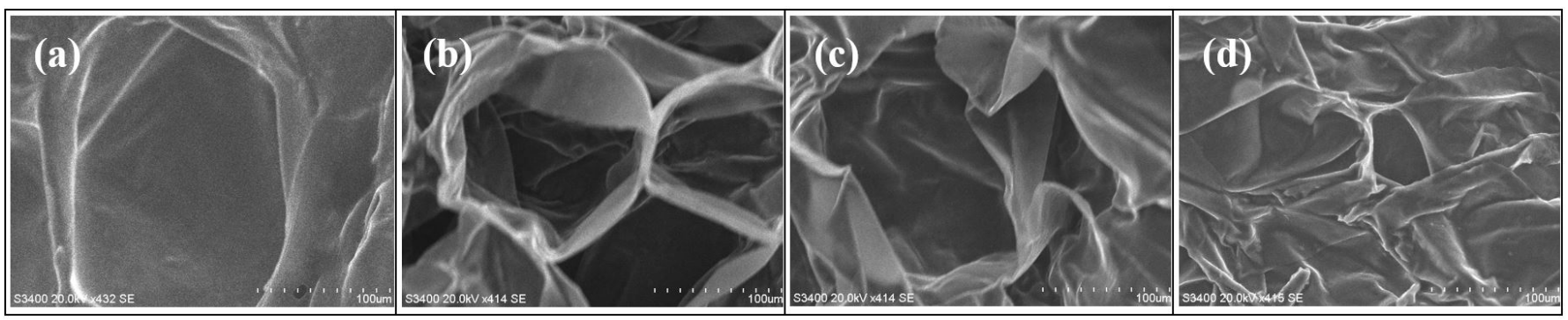

Figure 7. Scanning electron microscopy micrographs of apple samples at Magnification 415x: Fresh (a) and dried with microwave at 360W (b), $500 \mathrm{~W}(\mathrm{c})$, and $775 \mathrm{~W}(\mathrm{~d})$. 
higher deformation. This behavior can be explained by rapid kinetics of evaporation, leading to a faster diffusion of water through the cells, generating turbulence. Turbulence leads to cells deformation, and possible destruction at high microwave power (Figure 6d).

On the other hand, Figure 7 shows a very significant reduction in tissue thickness with the increase in microwave power. High power during drying might led to a melting of the starch granules and hence affecting the starch-protein matrix, leading to structural destruction of the samples as seen in Figure 6-d. These structural changes are in agreement with previous research work, studying the effect of microwave power levels on drying of bamboo shoot (Bal et al., 2017), ginger (Izli \& Polat, 2019) and trabzon persimmon (Çelen, 2019).

\section{Conclusions}

In the present study, microwave drying characteristics of Gala apples (Malus Pumila) cylinders with different diameters $(10.5$ and $17.5 \mathrm{~mm})$ and thicknesses $(3.3,4.5$, and $6.0 \mathrm{~mm})$ at three microwave power levels $(360,500$, and $775 \mathrm{~W})$ were investigated. In total, eighteen different experimental conditions were studied. The Aghbashlo model, together with Page and logarithmic models, provided the best fit for the results among eight tested thin-layer models for all the runs. Increasing the microwave power decreased the drying time and increased the effective moisture diffusivity. The diameter of the apple samples had a similar effect as the power on the drying time and the effective moisture diffusivity. However, as samples thickness increases, effective diffusivity increases, but there was no clear trend on the drying kinetics.

The calculated effective diffusivity was between $1.47 \times 10^{-7}$ and $24.4 \times 10^{-7} \mathrm{~m}^{2} / \mathrm{s}$ and the activation energy was between 19.2 and $27.1 \mathrm{~g} / \mathrm{W}$ for the studied samples. An experimental design was used to express the drying time and the effective diffusivity as a function of the studied parameters. For the drying time, the power and the diameter are more significant than other variables. However, the thickness has the principal effect to increase the effective diffusivity. Thus, for higher drying rate, higher microwave powers and larger diameters are preferred.

Applying higher microwave power increased the surface color change and lowered the lightness of the dried samples, in addition to the occasional burning effect. Also, the high microwave power destroyed the surface structure, hence, avoiding high power is recommended to preserve textural quality of the product.

\section{References}

Aghbashlo, M., Kianmehr, M. H., \& Samimi-Akhijahani, H. (2009). Evaluation of thin-layer drying models for describing drying kinetics of barberries (Barberries Vulgaris). Journal of Food Process Engineering, 32(2), 278-293. http://dx.doi.org/10.1111/j.1745-4530.2007.00216.x.

Ando, Y., Hagiwara, S., Nabetani, H., Sotome, I., Okunishi, T., Okadome, H., Orikasa, T., \& Tagawa, A. (2019). Effects of prefreezing on the drying characteristics, structural formation and mechanical properties of microwave-vacuum dried apple. Journal of Food Engineering, 244, 170-177. http://dx.doi.org/10.1016/j.jfoodeng.2018.09.026.
Ashtiani, S.-H. M., Sturm, B., \& Nasirahmadi, A. (2018). Effects of hot-air and hybrid hot air-microwave drying on drying kinetics and textural quality of nectarine slices. Heat and Mass Transfer, 54(4), 915-927. http://dx.doi.org/10.1007/s00231-017-2187-0.

Association of Official Agricultural Chemists - AOAC. (2010). Official methods of analysis of the Association of Official Analytical Chemists (18th ed.). Arlington: AOAC.

Bal, L. M., Yogranjan, Naik, S. N., Satya, S., \& Kar, A. (2017). Changes in tissue structure and physico-chemical quality characteristics of bamboo shoot slices during microwave drying process. Journal of Food Measurement and Characterization, 11(3), 1203-1209. http:// dx.doi.org/10.1007/s11694-017-9497-2.

Balti, M. A., Hadrich, B., Kriaa, K., \& Kechaou, N. (2018). Lab-scale extraction of essential oils from Tunisian lemongrass (Cymbopogon flexuosus). Chemical Engineering and Processing: Process Intensification, 124, 164-173. http://dx.doi.org/10.1016/j.cep.2017.12.012.

Beaudry, C., Raghavan, G. S. V., \& Rennie, T. J. (2003). Microwave finish drying of osmotically dehydrated cranberries. Drying Technology, 21(9), 1797-1810. http://dx.doi.org/10.1081/DRT-120025509.

Ben Mabrouk, S., Benali, E., \& Oueslati, H. (2012). Experimental study and numerical modelling of drying characteristics of apple slices. Food and Bioproducts Processing, 90(4), 719-728. http://dx.doi. org/10.1016/j.fbp.2012.02.001.

Çelen, S. (2019). Effect of microwave drying on the drying characteristics, color, microstructure, and thermal properties of trabzon persimmon. Foods, 8(2), 84. http://dx.doi.org/10.3390/foods8020084. PMid:30813446.

Crank, J. (1975). The mathematics of diffusion (2nd ed.). Oxford: Clarendon Press.

Cuccurullo, G., Giordano, L., Metallo, A., \& Cinquanta, L. (2018). Drying rate control in microwave assisted processing of sliced apples. Biosystems Engineering, 170, 24-30. http://dx.doi.org/10.1016/j. biosystemseng.2018.03.010.

Darvishi, H., Asl, A. R., Asghari, A., Azadbakht, M., Najafi, G., \& Khodaei, J. (2014). Study of the Drying Kinetics of Pepper. Journal of the Saudi Society of Agricultural Sciences, 13(2), 130-138. http://dx.doi. org/10.1016/j.jssas.2013.03.002.

Dissa, A. O., Bathiebo, D. J., Desmorieux, H., Coulibaly, O., \& Koulidiati, J. (2011). Experimental characterisation and modelling of thin layer direct solar drying of amelie and brooks mangoes. Energy, 36(5), 2517-2527. http://dx.doi.org/10.1016/j.energy.2011.01.044.

Djekic, I., Tomic, N., Bourdoux, S., Spilimbergo, S., Smigic, N., Udovicki, B., Hofland, G., Devlieghere, F., \& Rajkovic, A. (2018). Comparison of three types of drying (supercritical CO2, air and freeze) on the quality of dried apple - quality index approach. Lebensmittel-Wissenschaft + Technologie, 94, 64-72. http://dx.doi.org/10.1016/j.lwt.2018.04.029.

Ertekin, C., \& Firat, M. Z. (2017). A comprehensive review of thinlayer drying models used in agricultural products. Critical Reviews in Food Science and Nutrition, 57(4), 701-717. http://dx.doi.org/10. 1080/10408398.2014.910493. PMid:25751069.

Fortes, M., \& Okos, M. R. (1981). Heat and mass transfer in hygroscopic capillary extruded products. AIChE Journal. American Institute of Chemical Engineers, 27(2), 255-262. http://dx.doi.org/10.1002/ aic.690270212.

Henderson, S. M., \& Pabis, S. (1961). Grain drying theory, II. Temperature effects on drying coefficients. Journal of Agricultural Engineering Research, 6, 169-174.

Hukill, W. V. (1954). Grain drying. In J. A. Anderson \& A. W. Alcock (Eds.), Storage of cereal grains and their products. St. Paul, Minnesota: Am. Ass. Cereal Chem. 
Izli, N., \& Polat, A. (2019). Effect of convective and microwave methods on drying characteristics, color, rehydration and microstructure properties of ginger. Food Science and Technology (Campinas), 39(3), 652-659. http://dx.doi.org/10.1590/fst.04518.

Izli, N., Izli, G., \& Taskin, O. (2017). Influence of different drying techniques on drying parameters of mango. Food Science and Technology (Campinas), 37(4), 604-612. http://dx.doi.org/10.1590/1678-457x.28316.

Khraisheh, M. A. M., Cooper, T. J. R., \& Magee, T. R. A. (1997). Microwave and air drying I. Fundamental considerations and assumptions for the simplified thermal calculations of volumetric power absorption. Journal of Food Engineering, 33(1-2), 207-219. http://dx.doi.org/10.1016/S0260-8774(97)00050-2.

Labuza, T. P., Mcnally, L., Gallagher, D., Hawkes, J., \& Hurtado, F. (1972). Stability of intermediate moisture foods. 1. Lipid oxidation. Journal of Food Science, 37(1), 154-159. http://dx.doi. org/10.1111/j.1365-2621.1972.tb03408.x.

Lewis, W. K. (1921). The rate of drying of solid materials. Journal of Industrial and Engineering Chemistry, 13(5), 427-432. http://dx.doi. org/10.1021/ie50137a021.

Orsat, V., Changrue, V., \& Raghavan, V. G. S. (2006). Microwave drying of fruits and vegetables. Stewart Postharvest Review, 2(6), 1-7. http:// dx.doi.org/10.2212/spr.2006.6.4.

Özbek, B., \& Dadali, G. (2007). Thin-Layer Drying Characteristics and Modelling of Mint Leaves Undergoing Microwave Treatment. Journal of Food Engineering, 83(4), 541-549. http://dx.doi.org/10.1016/j. jfoodeng.2007.04.004.

Page, G. E. (1949). Factors influencing the maximum rates of air drying shelled corn in thin layers (M. Sc. thesis). Purdue University, West Lafayette.
Polat, A., Taskin, O., Izli, N., \& Asik, B. B. (2019). Continuous and intermittent microwave-vacuum drying of apple: drying kinetics, protein, mineral content, and color. Journal of Food Process Engineering, 42(3), 1-7. http://dx.doi.org/10.1111/jfpe.13012.

Sallam, Y. I., Aly, M. H., Nassar, A. F., \& Mohamed, E. A. (2015). Solar drying of whole mint plant under natural and forced convection. Journal of Advanced Research, 6(2), 171-178. http://dx.doi.org/10.1016/j. jare.2013.12.001. PMid:25750751.

Sanga, E., Mujumdar, A. S., \& Raghavan, G. S. V. (2000). Principles and applications of microwave drying. In A. S. Mujumdar (Ed.), Drying technology in agriculture and food sciences (pp. 253-289). Enfield, USA: Science Publishers.

Sharaf-Eldeen, Y. I., Blaisdell, J. L., \& Hamdy, M. Y. (1980). A model for ear corn drying. Transactions of the ASAE. American Society of Agricultural Engineers, 23(5), 1261-1265. http://dx.doi.org/10.13031/2013.34757.

Sin Ying, H., Anuar, M. S., \& Mohd Nor, M. Z. (2018). Drying, colour and sensory characteristics of 'Berangan' banana (Musa Accuminata) flesh dried using a microwave oven. Malaysian Journal of Halal Research, 1(1), 10-14. http://dx.doi.org/10.26480/mjhr.01.2018.10.14.

Verma, L. R., Bucklin, R. A., Endan, J. B., \& Wratten, F. T. (1985). Effects of drying air parameters on rice drying models. Transactions of the ASAE, 28(1), 296-301. http://dx.doi.org/10.13031/2013.32245.

Wang, G. Y., \& Singh, R. P. (1978). Single layer drying equation for rough rice. Materials Science, 78-3001.

Zarein, M., Samadi, S. H., \& Ghobadian, B. (2015). Investigation of microwave dryer effect on energy efficiency during drying of apple slices. Journal of the Saudi Society of Agricultural Sciences, 14(1), 41-47. http://dx.doi.org/10.1016/j.jssas.2013.06.002. 